\title{
Arqueología aplicada y patrimonio: memoria y utopía
}

\author{
Applied Archaeology and Heritage: memory and utopia
}

\author{
David BARREIRo \\ Instituto de Ciencias del Patrimonio (INCIPIT) \\ Consejo Superior de Investigaciones Científicas \\ Edificio Monte da Condesa, bajo \\ USC Campus Sur \\ 15782 Santiago de Compostela \\ david.barreiro@incipit.csic.es
}

Recibido: 04-06-2012

Aceptado 28-08-2012

\begin{abstract}
RESUMEN
Se presenta una reflexión que intenta contribuir a la plena integración de la arqueología en una estrategia de estudio, gestión y socialización integral del patrimonio. Para ello se perfila el campo conceptual mediante una aproximación a los conceptos de registro y patrimonio. Se plantea, desde la dialéctica, la necesidad de teorizar sobre las capacidades reales de una acción crítica dentro del campo del patrimonio. Para ello, se proponen como pasos ineludibles la necesidad de generar una estrategia teórica que propicie la colaboración entre los distintos sectores que conforman la disciplina; la cooperación estrecha entre las diversas ciencias que tienen al patrimonio por objeto de estudio; la cooperación con otras disciplinas que trabajan con campos complementarios al del patrimonio (ordenación del territorio, medio ambiente) y la ampliación de la estrategia para la incorporación de otras disciplinas que toman al patrimonio como medio para su ejercicio. Finalmente, se deconstruye el concepto de valor patrimonial en sus diferentes dimensiones, abogando a continuación por una acción que tenga como horizonte utópico la plena socialización de las ciencias del patrimonio (incluida la arqueología) y la puesta en valor del mismo patrimonio, entendida en términos de un acrecentamiento de su relevancia y poder transformador de la realidad social.
\end{abstract}

Palabras Clave: Arqueología aplicada. Dialéctica del Patrimonio. Gestión Integral del Patrimonio. Socialización del Patrimonio.

\begin{abstract}
We present a reflection that contributes to the full integration of archeology in a strategy of study, management and comprehensive socialization of heritage. This field is outlined by a conceptual approach to the concepts of record and heritage. Arises from the dialectic, we need to theorize about the actual capacity of a critical action in the field of heritage. This is proposed as an unavoidable steps necessary to generate a theoretical strategy that encourages collaboration between different sectors within the discipline, the close cooperation between the various sciences that are designed to study heritage, cooperation with other disciplines working with heritage complementary fields (planning, environment) and the extension of the strategy for the incorporation of other disciplines who take the heritage as a means for its exercise. Finally, we deconstruct the concept of heritage value in its different dimensions, an advocate for an action which has as its utopian horizon full socialization of science heritage (including archeology) and of the same heritage, understood in terms of a enhancement of their relevance and transforming power of social reality.
\end{abstract}

KEY worDs: Applied Archaeology. Heritage Dialectic. Integrated Heritage Management. Heritage Socialization.

Sumario: 1. Introducción. 2. Arqueología, registro, patrimonio, memoria. 3. Dialéctica del patrimonio. 4. Integración intradisciplinar y cooperación interdisciplinar. 5. Hacia un socialización del patrimonio. 6. Arqueología, patrimonio, utopía. 


\section{Introducción}

Desde el último tercio del siglo XX, en España se han venido produciendo algunos fenómenos (en buena medida paralelos a los de otros países de nuestro entorno) que justifican la necesidad de reflexionar sobre el papel de la arqueología como disciplina científica y práctica social:

1) La diversificación de la arqueología en varios sectores con funciones e intereses diversos. Aunque no son compartimentos estancos, se distinguen una academia que investiga, un sector profesional independiente que aplica la gestión (generalmente en el marco de relaciones de mercado; Parga-Dans y Varela 2012) y una administración que supervisa y gestiona la documentación generada (Barreiro 2006b).

2) La consolidación de un campo científicotécnico en torno al patrimonio y los procesos de patrimonialización, que implica a) la progresiva transformación del concepto de patrimonio, que cada vez integra más entidades, y en el que cada vez intervienen más agentes y con más peso (Fairclough 2009) y b) la necesidad de incrementar la cooperación entre las disciplinas que tienen al patrimonio como objeto de estudio (como problema científico), a las que denominaremos 'ciencias del patrimonio'.

3) La progresiva implementación de políticas de gestión del patrimonio, muchas veces insertas en políticas que las engloban, relacionadas con la gestión del medio ambiente y el territorio, en las que también intervienen otras disciplinas, aunque no tengan al patrimonio como objeto de estudio.

4) El aumento paulatino del interés por el patrimonio y sus valores por parte de agentes sociales no vinculados profesionalmente a su estudio y gestión, y la progresiva toma de conciencia desde las instituciones de investigación de la necesidad de estrechar la relación entre la actividad científica y el contexto social.

5) La generalización, en el marco de la globalización capitalista, de procesos de homogeneización, deslocalización, hibridación y mediatización del patrimonio (Hernández 2005: 123-158), al tiempo que se han incrementado los movimientos de resistencia identitaria y los procesos de reivindicación de lo local, de autogestión y de empoderamiento (control sobre los recursos materiales y simbólicos) como alternativa a la expansión de modos y medios de vida no sostenibles. Con la crisis en la que nos hallamos, estos últimos procesos se han acelerado, aunque siguen sin tener, apenas, relevancia social.
La arqueología debe reflexionar sobre cuál debe ser su rol en estos contextos. Nuestra intención es apuntar algunas claves en relación con la necesidad de perfilar e implementar una estrategia patrimonial que permita:

1) a) Precisar la definición del campo conceptual patrimonial y los procesos dialécticos que en dicho campo se producen, y b) posibilitar la cooperación transdisciplinar entre las distintas ciencias del patrimonio.

2) En lo que respecta a la arqueología: minimizar las tensiones y contradicciones internas entre los distintos sectores que conforman la arqueología y potenciar los beneficios de la cooperación intradisciplinar.

3) Ampliar la cooperación interdisciplinar para integrar a todas aquellas disciplinas que se aplican en contextos de gestión del medio ambiente y el territorio (ciencias del medio ambiente, geografía, sociología, economía) en los que también se aplican las ciencias del patrimonio.

4) Integrar en la estrategia patrimonial a disciplinas que, aun no teniendo al patrimonio ni a los procesos de patrimonialización como objeto de estudio, sí que intervienen directamente en los procesos de extensión de una conciencia patrimonial (entendiendo por esto el proceso mediante el cual un agente social cobra conciencia de la existencia de la realidad patrimonial y de sus implicaciones). Estas disciplinas están relacionadas con la educación patrimonial (ciencias de la educación) y con la mediatización del tópico patrimonial (ciencias de la información).

5) Incrementar la relevancia política y social de las ciencias del patrimonio (entre ellas, la arqueología, que en este contexto entendemos como arqueología aplicada) y del mismo patrimonio, y su poder de transformación de la realidad en el marco de los procesos que están teniendo lugar en la actualidad. Esto, que es nuestro horizonte, es lo que denominamos 'socialización del patrimonio'.

\section{Arqueología, registro, patrimonio, memoria}

La arqueología es una disciplina que estudia los procesos sociales a través de su cultura material, lo que hace que sea válida para un determinado segmento de la realidad: para algunas realidades ya desaparecidas, como las sociedades prehistóricas, la cultura material es el único elemento en el que fundar un análisis social. Lo que no significa que la arqueología no pueda generar conocimiento a par- 
tir de la cultura material de otras sociedades (desaparecidas o no), ni que no haya otras disciplinas que también pueden aportar conocimiento sobre los contextos prehistóricos (las ciencias paleoambientales, la paleontología).

La arqueología se basa en la generación de un registro sistemático de las entidades identificadas en el proceso de trabajo. Por recurrir a un manual ya clásico (Renfrew y Bahn 1993: 43-4), el registro arqueológico está formado tanto por los artefactos y las estructuras (más simples o más complejas) como por los ecofactos, o restos orgánicos y medioambientales de la actividad humana.

Sin entrar en detalles, que han sido analizados en un libro de reciente aparición (Criado 2012: 62110 y 181-197), el 'registro arqueológico' es uno de los conceptos supervivientes (quizás el más importante) de la Nueva Arqueología. Sigue siendo un concepto clave, pero ha experimentado cambios importantes: hoy por hoy se basa, esencialmente, en la identificación de una estratigrafía y en la contextualización de la cultura material, las relaciones entre los elementos que la componen y los ecofactos.

La arqueología puede estudiar no sólo los restos materiales de la acción humana afectados por procesos deposicionales y postdeposicionales (Criado 2001: 39), sino cualquier entidad de la cultura material (por ejemplo, un edificio histórico en sus diversas fases constructivas). A la inversa, esto no significa que no haya más disciplinas que puedan estudiar el mismo objeto según sus propias metodologías y preguntas de investigación (por seguir con el ejemplo: la historia del arte se basará en el análisis iconográfico y de estilo; la arquitectura en conceptos estructurales; la historia en los documentos asociados a los contextos de construcción, uso y abandono). El objeto de estudio no demarca el campo de acción disciplinar.

En líneas generales, se puede decir que la arqueología genera, a partir del registro y junto a otras disciplinas, conocimiento histórico (contribuyendo a la interpretación crítica de la acción social pretérita) y antropológico (contribuyendo a la comprensión crítica de la acción humana). El campo de acción disciplinar no determina el tipo de conocimiento que se genera (en una excavación, por ejemplo, no sólo se genera conocimiento histórico), aunque sí hay conocimientos específicos que sólo puede producir una determinada disciplina científica.

El registro es una construcción científica (también es una construcción social, pero social en tanto que científica), para la que se precisan una serie de conocimientos teóricos, de método y prácticos (destrezas, técnicas y metodologías) que sólo pueden adquirirse en el seno de una formación especializada. Sólo recientemente parece que se empiezan a paliar las carencias de la universidad española en este terreno ${ }^{1}$.

Las definiciones de 'patrimonio arqueológico' que podemos encontrar suelen ser circulares: es patrimonio arqueológico aquello susceptible de ser estudiado con metodología arqueológica. Esta circularidad impide plantear nuestra estrategia integral partiendo de esta definición, ya que 1) no permite distinguir entre registro y patrimonio, y 2) no define patrimonio arqueológico ontológicamente, sino epistemológicamente. En realidad, las definiciones de patrimonio arqueológico son circulares porque no hay otra manera de definirlo más que acudiendo a la disciplina que contribuye de forma principal a su producción. No es un problema de la definición, sino de concepción: la separación convencional de diferentes tipos de patrimonio (tangible e intangible, arqueológico, etnológico, documental...) no puede fundamentar una estrategia de estudio integral del patrimonio, porque éste es más complejo que un simple conjunto de entidades clasificables, y una misma disciplina, como, por ejemplo, la arqueología, puede estudiar entidades convencionalmente adscritas a otras disciplinas (patrimonios etnográfico, artístico, etc.). Por lo tanto, de aquí en adelante hablaremos de patrimonio en general, no de patrimonio arqueológico, aunque sí nos centraremos en cómo la arqueología puede y debe intervenir, por ser una ciencia del patrimonio más, en una estrategia patrimonial integral.

El patrimonio se nutre del registro (generalmente transformado en conocimiento, aunque puede ser sólo información, archivada pero no interpretada), pero no sólo de él: si el registro es una construcción científica, el patrimonio es una construcción social, no sólo científica (y, en bastantes ocasiones, ni siquiera principalmente). Aun así, resulta difícil desgajar o discernir dónde acaba la arqueología (la práctica y el registro) y empieza el patrimonio:

The role of archaeologist as a developer of narrative, and as a resource of evidence for the public to use in narrative development makes it almost impossible to extract archaeology from heritage. As soon as the interpretation begins, the archaeologist begins to work in the field of heritage; it is the narrative nature of the archaological process that intertwines archaeology and heritage (Kenny 2009: 217).

Aunque varios autores han tratado de forma específica el tema de la producción de valor patrimonial (que más abajo retomaremos en detalle) seguiremos aquí la reciente conceptualización de 'entidad patrimonial' de González-Pérez y ParceroOubiña (2011). Para que una entidad (que denominan entidad primaria, con un carácter discreto) 
pueda ser considerada patrimonial tiene que darse una producción de valor. Este valor (que es multidimensional, como veremos) se le confiere socialmente, bien desde el ámbito del conocimiento experto (sea desde la administración, sea desde el campo científico-técnico), bien desde el ámbito de los no expertos: los agentes sociales, con toda su heterogeneidad (sea desde la apreciación distante, como le puede suceder a un turista; sea desde la proximidad y desde una relación de identidad y continuidad, como le puede suceder a un convecino). No hay un saber patrimonial específico (cfr. Bermejo 2007: 317), sino un campo social en el que confluyen todos estos agentes en un proceso de producción y agregación de valor.

"En cualquier caso la definición de patrimonio cultural es siempre abierta, negociable, dialógica, transformable y reflexiva. Y en la misma participan distintos operadores sociales que van desde organismos internacionales, responsables políticos e institucionales, empresas, expertos y científicos, hasta asociaciones, grupos o individuos" (Santamarina 2005: 48).

El patrimonio cultural es, por lo tanto, un producto (está formado por entidades, materiales o no) y la patrimonialización es el proceso, valorativo, que lo genera. 'Producto' y 'proceso' no son conceptos excluyentes, al igual que 'objeto' y 'acción' (Fairclough 2009: 29), aunque ciertas posiciones críticas, como la que sostienen Waterton y Smith (2009), remarcan el carácter procesual del patrimonio hasta el punto de minimizar, relativizar (e incluso negar) su condición de entidad objetivable ("There is no such thing as Heritage"; Waterton y Smith 2009: 10-28).

Los procesos de patrimonialización germinan a partir de una atribución de valor social a una entidad dada. Aunque los procesos que se activan en el aprecio a dicha entidad pueden funcionar individualmente, lo que convierte a una entidad en patrimonial es su carácter social. Si no, estaremos ante otro tipo de procesos, igualmente vinculados a la memoria y la identidad, pero vinculados a una esfera reducida (el individuo, la familia; aunque, de hecho, el concepto de 'patrimonio' se origina en estos contextos).

Un término que quizá merecería haber tenido más éxito fuera del campo de la antropología es el propuesto por Prats (1997): 'activación patrimonial', que transmite la idea de 'proceso' sin renunciar a la de 'producción', a partir de un momento y en torno a una entidad. En ocasiones acudiremos a él.

Es cierto que las definiciones y normativas institucionales clásicas sobre el patrimonio (provenien- tes de organismos internacionales como UNESCO o ICOMOS, o de las distintas administraciones) han presentado siempre un sesgo instrumental derivado de la perspectiva de los expertos que las han realizado, lo que Waterton y Smith (2009: 12-5) denominan Authorized Heritage Discourse (traducido como Discurso Patrimonial Autorizado, DPA, en Smith 2011), provocando la ilusión de que el patrimonio tiene un valor por sí mismo, un valor intrínseco (Mason 2002:8; Waterton y Smith 2009:10-27; González-Pérez y Parcero-Oubiña 2011; Villaseñor 2011), y que la función de los expertos es salvaguardarlo (y, en el mejor de los casos, divulgarlo). Esto, que podríamos denominar 'fetichismo patrimonial', sigue siendo una actitud muy extendida (por no decir hegemónica) en el campo de los expertos en patrimonio (a pesar de que documentos como el Convenio de Faro suponen un muy considerable avance dentro del mismo DPA, como se puede ver en las diversas contribuciones de VV.AA. 2009 y en Convenio de Faro 2005). Sin embargo, un bien patrimonial no es valioso por ser patrimonial, sino que es patrimonial porque es valioso. Es la sociedad, directamente o a través de las instituciones (los expertos de las instituciones son subsidiarios de las instancias políticas, y aquí se daría una primera contradicción, ya que el DPA se origina en instancias políticamente legitimadas para emitirlo), quien hace que una entidad discreta, una entidad primaria, adquiere una valor patrimonial. Y este valor emerge en

\footnotetext{
"un proceso cultural que tiene que ver con la negociación de la memoria, la identidad y el sentido del lugar" (Smith 2011: 42).
}

En un texto en el que conectaba el tópico patrimonial con el psicoanálisis, Castilla del Pino (1995: 9-14) señalaba que el sujeto es interacción y es biografía, es cultura y es historia. Nuestra historia personal es nuestra memoria, necesaria para la construcción permanente de nuestra identidad: esa construcción necesita conservar lo vivido, aunque esta vivencia haya sido almacenada/archivada (subconsciente: lo olvidado-oculto) o destruida (enfermedad psíquica: lo olvidado-destruido).

Esta relación entre individuo y sociedad, entre memoria personal y memoria colectiva, no sólo es metafórica (si la historia es la maestra de la vida, la arqueología es la psicoanalista de la historia) sino metonímica: la memoria colectiva se nutre, por una parte, de la agregación e interacción sucesiva de múltiples memorias personales desde tiempo inmemorial (valga la paradoja) aunque esto no quiere decir que sea una simple adición de memorias individuales, en tanto la memoria colectiva es una práctica socialmente construida que selecciona, transfor- 
ma, manifiesta y representa socialmente. Además, y por otra parte, la memoria colectiva se construye y re-construye a partir de elementos que son testimonio de la existencia de quienes nos precedieron y de nuestro propio pasado (la cultura material) lo que incluye no sólo lo que se ha mantenido a través del tiempo, y nos dota (en sentido antropológico, no cultural: esto es válido para cualquier sociedad y cultura) de identidad, sino lo que se ha olvidado, y ha hecho que nuestra identidad sea la que es (fluida e inaprensible tanto como queramos) y no otra.

El patrimonio (en este caso, el arqueológico) es identidad porque es memoria y olvido materializados:

"la memoria de la otredad se nos presenta sólo en forma de materia, sea ruina, resto o efecto de la acción pretérita" (Criado 2001: 40).

Negociar lo que somos y estamos en trance de ser (como negociación siempre en proceso e inacabada) implica tanto exhumar lo que está oculto y construir identidad en torno a ello, como re-generar identidades en torno a lo que ya estaba ahí y no era percibido, o era percibido de forma distorsionada. Un ejemplo nítido es el de los procesos de re-identificación, y de re-generación de identidad y de sentido del lugar de la población rural de algunas zonas de Uruguay con su patrimonio indígena, antes inexistente para ellos, a partir de la restitución arqueológica de una memoria que había sido tronzada, y que ha sido re-construida ${ }^{2}$. La memoria se refiere a personas y acontecimientos del pasado, pero se construye socialmente (incluso la propia ocultación de la historia en determinadas sociedades es una estrategia de memoria) en torno a espacios, a lugares y a objetos del presente (esto no es exclusivo de la sociedad moderna, como señala, por ejemplo, Harvey 2001; pero el modo de patrimonialización en que se produce, sí, porque se asocia a una conciencia del cambio y de la pérdida que sí son específicamente modernas; Berman 1988) y la arqueología, en tanto saber científico, puede y debe contribuir a ello; es más: es parte de ello:

Such technological change, therefore, has led to an increasing bulk and capacity to store, articulate and produce heritage, just as changing leisure practices have allowed greater scope to interpret and 'do' heritage. In this respect, heritage is not seen as a new phenomenon, nor even one particularly or exclusively associated with modernity. Rather, the transformations that are implied by modernity are simply mirrored by an increasing intensification, recycling, depth and scope of heritage activity. In many respects therefore, the present tendency for nostalgia and finding solace in heritage is just the latest phase of a much longer trajectory (Harvey 2001: 338)

Pero este pensar en el pasado nos devuelve al presente (puesto que es una conciencia siempre presente) y, por lo tanto, al futuro (ya que, si admitimos la existencia de un pasado, reconocemos la posibilidad de un futuro). La pregunta de los expertos suele ser “¿Qué podemos hacer por el patrimonio?”, pero las preguntas deberían ser: “QQué podemos hacer nosotros, la humanidad, por nosotros mismos, a través del patrimonio? ¿Qué podemos hacer los expertos para contribuir a ello?"

\section{Dialéctica del patrimonio}

A pesar de que el trabajo con el patrimonio tiene un componente utópico y de transformación, las contradicciones que lo atraviesan, en tanto producto (y más en cuanto al modo de patrimonialización que al hecho patrimonial en sí) de la modernidad (Hernández 2008), para algunos autores son insalvables y llegan incluso a su mismo núcleo conceptual: nunca podrá ser una herramienta crítica porque es parte del sistema que se pretende criticar o transformar (Lull 2007: 120).

Estas críticas proceden, supuestamente, de autores (Lowenthal, citado en Bermejo 2007, Watson 2009: 29 y Harvey 2001; Harrison o Ashworth, citados en Watson 2009: 29; Hewison, citado en Harvey 2001) que, en nuestra opinión, entrarían dentro de lo que Eco (1968) denominó en su momento "apocalípticos" (o, para Raphael Samuel, "Heritage baiters", según Harvey 2001 y Kenny 2009), y que para él eran aquellos intelectuales (Ortega y Gasset, Adorno, Arendt) que, siguiendo más o menos la estela de Nietzsche, reniegan de la cultura de masas y de la industria cultural, paradigma de la cosificación y espectacularización propias de la sociedad de consumo. Para los autores que hemos señalado (aunque la interpretación que se ha hecho de los mismos haya sido, a veces, no muy acertada, como señala Azkarate 2009: 292-3 para el caso de Lowenthal) el patrimonio es también un producto, pervertido desde su origen por los propios procesos modernos de objetivación-reificación y mercantilización.

En nuestra opinión, y, de acuerdo con Harvey (2001:323), estas críticas parecen sugerir que hay una narrativa histórica "correcta" (que el patrimonio destruye) y que esa narrativa histórica era más auténtica y genuina que la mediatizada por el patrimonio. El propio Harvey (2001) hace una reflexión sobre procesos de relectura y apropiación del pasado (de patrimonialización, en definitiva) en 
épocas premodernas, y lo ejemplifica, entre otros, con la reedificación de San Pedro del Vaticano; para Lowenthal, la reutilización de materiales de la basílica anterior significa que esas piedras no significaban nada para los constructores e ingenieros del Renacimiento; Harvey replica que, sin embargo, la basílica no se movió de sitio, porque es el sitio en el que ya se emplazaba la basílica lo que estaba cargado de valores "patrimoniales". Lo mismo sucedió con la cristianización de multitud de lugares en todo el mundo. Aun así, esto no invalida el argumento de que el patrimonio es un concepto moderno: porque es en la modernidad cuando el objeto en sí (en este caso, la basílica renacentista) deviene en patrimonial, en elemento agregado a un lugar de memoria hasta el punto de suplantarlo (ésta es la reificación moderna) y de imponer sus propios valores; lo que no significa que desde entonces no se haya ido modificando la forma en que la basílica de San Pedro es percibida, experimentada y utilizada.

Por otro lado, cabe preguntarse si es coherente renegar de la industria cultural formando parte de ella; a no ser que estos autores apocalípticos consideren que vender sus libros no es mercantilizar su conocimiento. Porque, si es así, si creen que hay una industria cultural comercial cosificadora para las masas totalmente discernible de otra cultura liberadora para los individuos, independientemente de que las dos cuesten dinero, entonces hay que preguntarse por qué no aplican la misma distinción cuando se refieren al patrimonio.

Otro intelectual (Debord 1999 -el original es de 1968-), aunque no se refería en concreto al patrimonio, salvo en un pasaje al que ya nos hemos referido en otras ocasiones (Barreiro 2006b), acuñó el concepto de 'Sociedad del Espectáculo' (una hipótesis situacionista sobre la cultura de masas). Estas críticas al patrimonio también se pueden enmarcar en esta crítica general de la sociedad del espectáculo, pero difieren de ella en que la crítica de Debord es una crítica global del funcionamiento del capitalismo tardío, no de uno de sus fenómenos en particular. Aun así, como señala Huyssen (2002: 25), la tesis de la sociedad del espectáculo olvida algo tan obvio como que "la sociedad de la vivencia entretenida no carece de una realidad vivida sustancial".

Frente a los apocalípticos, Eco situó a los "integrados" (Schlesinger y Bell entre otros), intelectuales que ven la cultura de masas como algo intrínsecamente positivo y democratizador, en muchos casos sin ninguna perspectiva crítica. En lo que nos afecta (el patrimonio) existen numerosos ejemplos de autores que tienen una visión aproblemática (en un sentido conceptual y axiológico, no práctico ni técnico) del patrimonio. Se podrían citar multitud de fuentes provenientes de contextos instituciona- les, es decir, cualquiera de las normativas y recomendaciones emitidas en el marco del DPA. Entran aquí un buen número de propuestas teóricas, técnicas y metodológicas, esencialmente provenientes de organismos patrimoniales del ámbito anglosajón (English Heritage, Heritage Council -Irlanda-, National Parks Service -EE.UU.-, Australian Heritage Council, por citar algunos; un buen ejemplo son las secciones correspondientes a Arqueología y Patrimonio Cultural de los volúmenes 10 y 11 del Design Manual for Roads and Bridges, editado por Highways Agency, del Reino Unido, que es constantemente actualizado en su página web).

Este punto de vista pragmático, para el que sólo existen los problemas prácticos, técnicos y metodológicos, y no existen los meta-problemas, que conciernen a la misma esencia de la patrimonialización, sigue siendo hegemónico entre los expertos.

Pero un amplio campo se abre entre las dos posiciones referidas. El patrimonio, en tanto producto moderno, es ambivalente, porque lo construimos nosotros, y en él conviven, como en casi todo campo social moderno, luces y sombras, las mismas que constituyen la propia modernidad (siguiendo la hipótesis de Berman 1988). En nuestra opinión, el patrimonio, como la cultura de masas de la que forma parte, no es una opción; es (parte de) la realidad. De lo que se trata no es de interpretarla, sino de transformarla ${ }^{3}$.

Por lo tanto, parece razonable adoptar un punto de vista más dialéctico: no se trata de negar las visiones radicales (aparte de las incoherencias de posicionamiento de algunos discursos, la profundidad crítica sigue siendo relevante y necesaria para saber en qué coordenadas nos movemos), ni de asumir las propuestas pragmáticas sin reflexionar sobre las implicaciones de la patrimonialización, sino de incorporar la perspectiva crítica a nuestras propuestas. Como consecuencia de esto hemos de asumir, también, que el concepto de patrimonio ha recorrido el mismo camino que el concepto de modernidad: igual que el discurso de la modernidad es una imposición de la cultura occidental al resto del mundo, así ocurre con el patrimonio. El concepto de patrimonio está asociado al propio proceso de expansión de la modernidad y, por lo tanto, al colonialismo. La cuestión es: ¿existe una alternativa viable a la gestión moderna -en cualquiera de sus formas- de la realidad, incluida la realidad del patrimonio? Nosotros creemos que no, que cualquier alternativa a la modernidad (por suerte o por desgracia) no puede emerger sino dentro de sí misma, y que, por lo tanto, lo que hay que perseguir son formas de patrimonialización que propicien la generación de tensiones dialécticas en el propio seno del discurso modernizador. 
Aunque no todos los autores que se podrían incluir en este campo intermedio reflexionan sobre las contradicciones del patrimonio, ni lo hacen desde un punto de vista dialéctico, sí suelen ser conscientes de las dificultades de trabajar con un concepto susceptible de manipulaciones ideológicas e identitarias (Moncusí 2005), y, sobre todo, de cosificaciones y mercantilizaciones sin escrúpulos (Herrero 2011; Pereiro 2006). De las contradicciones (que algunos denominan paradojas, lo que podría llevarnos a otra discusión) inherentes a la producción de patrimonio dan cuenta autores como Prats (1997), García Canclini (1999), Hernández (2008) o Ariño (2010).

\section{Integración intradisciplinar y cooperación interdisciplinar}

Desde los años ' 80 , las necesidades derivadas de la consideración de las entidades patrimoniales como bienes públicos hicieron que la administración central y, posteriormente, las autonómicas, asumiesen la tarea de protegerlo y difundirlo. Esto implicó un radical cambio de estatus en la relación de la sociedad con el patrimonio. Porque es a través de la mediación política, de la administración en tanto depositaria de la voluntad popular (tampoco entraremos en disquisiciones al respecto ahora), que el patrimonio empezó a ser gestionado de forma sistemática. Dejó de ser un conjunto muy vago, y muy reducido, dado que el patrimonio lo constituían sólo contados elementos ya socialmente valorados por sus especiales características (monumentalidad, valor simbólico y, ya entonces, atractivo turístico), a ser un conjunto de entidades en expansión y sistemáticamente clasificado e introducido como un elemento más en normas de diferente naturaleza (específicas, territoriales, ambientales) y rango.

Por otro lado, este cambio provocó que la academia, salvo contadas excepciones, se desentendiese de la problemática relativa a la gestión del patrimonio. Algunos de los problemas que han aquejado a la arqueología profesional no académica en estos años (la no publicación de las memorias, la indefensión ante sus clientes) han sido consecuencia de este desentendimiento inicial, que impidió cualquier nexo entre el inmenso registro producido en el marco de la gestión del patrimonio (la arqueología preventiva y de rescate, y la arqueología de revalorización) y su investigación (incluyendo la posibilidad de generar un campo de investigación aplicada para optimizar esta gestión en términos de producción y socialización de conocimiento).

Un primer paso para la reintegración, que sólo recientemente se ha empezado a dar de forma ge- neralizada, sería dar legitimidad científica a los arqueólogos que trabajan en el sector privado. Derivado de ello se tiene que generalizar una formación especializada de calidad (Castillo 2006; Querol 2011) incidiendo en la formación teórica y práctica para desempeñar la profesión en cualquier ámbito, sea dentro o fuera de la academia.

La realidad, hasta el momento, es que el capital humano que se ha ido generando en estos últimos treinta años, mejor o peor formado, y que ha nutrido el sector profesional privado (hasta formar un auténtico "territorio profesional", como señala Kenny 2009:220-222), se ha visto desprotegido, en manos de intereses económicos (sus clientes) muchas veces opuestos a los que éticamente deberían (deberíamos) defender (cuestión muy compleja que no abordaremos aquí, y que no es exclusiva de la arqueología: Arévalo y Díaz 1997). Y en manos de intereses políticos casi siempre complacientes con dichos intereses económicos o, en el mejor de los casos, promotores de grandes dispositivos patrimoniales inspirados por una lógica espectacular. Con la crisis económica, esta situación no ha hecho sino agravarse (Schlanger y Aitchison 2010).

En el nivel intradisciplinar, por lo tanto, se hace necesaria una reintegración, en el sentido de una aproximación, entre los diferentes sectores, en dos niveles: táctica, que se puede materializar en proyectos en los que el patrimonio sea el campo común, y estratégica, maximizando las potencialidades de cada sector y las posibilidades de que los restantes se beneficien de ello.

Como dijimos más arriba, el campo del patrimonio es contradictorio de por sí; pero mucho más si lo contextualizamos en los procesos de modernización del territorio, en un contexto cambiante en el que ha primado y prima una lógica modernizadora expansiva y de transformación continuada de la vida social. Pese a ello, la administración se ha ido dotando de instrumentos que, con más o menos eficacia, dependiendo mucho de la voluntad política y de la fortaleza de los intereses económicos en cada contexto, pretende mantener cierto control sobre los procesos de modernización.

Nos referimos a campos como el de la ordenación del territorio o la evaluación ambiental, cuyas contradicciones ya hemos analizado en otros lugares (Barreiro 2006a, 2006b, 2009), y no sólo nosotros (Rodríguez Temiño 1998; Cerdeño et al. 2005). La desconexión entre estos contextos (ordenación del territorio, evaluación ambiental) y los agentes sociales es un signo más de la distancia existente entre la administración, dominada por la cultura tecnocrática de los expertos (el problema no surge sólo en torno al DPA) y la ciudadanía (o, al menos, parte de ella). 
En los últimos años se han ido incorporando nuevas normas relativas a la necesidad de incrementar la participación pública en estos procedimientos, normas que posibilitan, en teoría, ese acercamiento. La realidad es que son normas de difícil aplicabilidad, máxime teniendo en cuenta que parten de la discutible premisa de que los agentes sociales están informados de su capacidad y gozan de autonomía política. En este campo, es tarea de la academia elaborar propuestas teórico-metodológicas para la implicación activa de la arqueología en la implementación de las políticas territoriales y ambientales (directrices de ordenación del territorio, evaluación de impacto ambiental, evaluación ambiental estratégica, protección y gestión del paisaje, sostenibilidad, participación pública). En nuestra opinión, lo deseable sería que el patrimonio hubiese sido objeto de una gestión pública en el marco de una "política de satisfacción de valores de uso" (Lull 2007: 122), al modo en que (con las debidas cautelas, en las que no entraremos ahora) se ha venido haciendo en otros países, como Francia o Noruega, pero nuestra realidad política ha sido y es otra. En este contexto, la academia no puede plantear como una salida lícita realizar una enmienda a la totalidad y desentenderse del problema (salvo que se opte por una intervención directa en la política).

Creemos que nuestra propuesta de una arqueología aplicada y una gestión integral del patrimonio (aproximando a los distintos sectores de la disciplina y a las distintas disciplinas patrimoniales implicadas) necesita, además, una activa colaboración con las distintas disciplinas que también participan en los procesos de gestión del territorio y el medio ambiente. La investigación en arqueología también debe orientarse, por lo tanto, hacia un incremento de los medios de colaboración interdisciplinar (proyectos y redes) y hacia el desarrollo de metodologías y criterios de actuación comunes en el marco de estas políticas de control, precisamente para que sean políticas, y no meros engranajes del sistema tecnocrático.

\section{Hacia un socialización del patrimonio}

El concepto de 'socialización', o de 'puesta en valor', requeriría, por sí solo, un análisis para el que no tenemos espacio. No obstante, trataremos de aportar algunas claves que permitan entender mejor nuestra propuesta.

\subsection{El valor del patrimonio}

Los equívocos que se generan en torno al concepto de 'puesta en valor' son una de las tres razones por las que, desde hace tiempo, tratamos de utilizar de forma preferente el concepto de 'socialización', aunque en esencia nos estamos refiriendo a lo mismo: a la carga sucesiva de valores que implica el trabajo en y con el patrimonio hasta que adquiera relevancia social.

La segunda razón es que del concepto de 'puesta en valor', entendido como culminación de un proceso (la 'cadena de valor', Criado 1996) de estudio y gestión del patrimonio (González Méndez 1999), se puede desprender la idea de que sólo en esa fase final la entidad patrimonial adquiere un valor, de forma que se desvirtúa el propio concepto de 'cadena de valor' (entendida como una concatenación de acciones sobre y con el patrimonio que implican una carga sucesiva de valor, desde su inicio hasta su final, -final abierto, pero ésa es una cuestión en la que no entraremos ahora-). De hecho, como señalan González-Pérez y Parcero-Oubiña (2011:236), una activación patrimonial se produce desde el mismo momento en que un sujeto (un experto o cualquier otro sujeto social), selecciona una entidad discreta y le da un valor patrimonial (más abajo veremos cómo se puede desgranar este proceso, cómo podemos saber cuándo una adjudicación de valor a una entidad dada deja de ser un asunto individual para pasar a ser un asunto social y, por lo tanto, patrimonial en este sentido). La propia selección es ya un acto valorativo (como señalaba Kenny 2009:217, citado en el apartado inicial). El concepto de 'cadena de valor', de hecho, requiere ser revisado a la luz de estas nuevas aportaciones, que inciden en que el proceso de valoración no se inicia, necesariamente, con la adjudicación de valor por parte de un científico. Aun, en muchos casos, esa identificación es preexistente a toda intervención experta, ya que forma parte del sustrato cultural y se encarna en la existencia de entidades que ya tienen un valor referencial, incluso aunque dichas entidades, en su materialidad, hayan desaparecido o estén ocultas. A través de la microtoponimia, por ejemplo, los elementos del patrimonio en Galicia (se conserven o no, sean visibles o no) han funcionado y siguen funcionando como elementos connotadores de un sentido del lugar, de una memoria colectiva encarnada en el espacio: Forno dos Mouros, Porta de Mámoa, Fuente de los Franceses... En muchas ocasiones, además, este sentido del lugar se refuerza con la existencia de leyendas o historias asociadas.

La tercera razón es que el concepto de 'socialización' tiene una connotación más genérica y estratégica que el de 'puesta en valor'. Funciona, como concepto, a un nivel más abstracto. Este concepto se amolda así mejor a la posibilidad de que se puedan articular políticas estratégicas de puesta en valor (socialización, en suma) del conjunto de 
los bienes que integran el patrimonio en un marco político dado.

$\mathrm{Y}$ es que el concepto de valor es esquivo. De hecho, Marx afirmaba que "el valor no lleva escrito en la frente lo que es", por eso dedicó la parte inicial de su obra capital a desentrañar los secretos del valor dentro del sistema productor de mercancías que es el capitalismo. Uno de los pilares de su análisis radicó en la relación entre valor de uso y valor de cambio, que él no inventó, pero sí deconstruyó. Obviamente, no somos competentes para evaluar aquí hasta qué punto sigue siendo válida esta distinción, pero, a juzgar por su recurrencia, al menos, parece una distinción de sentido común.

Cuesta entender, entonces, por qué el concepto de 'puesta en valor' genera tantos resquemores. $\mathrm{Si}$ el problema está en el término 'valor', está claro que bajo este concepto queda englobado el valor de uso (y, eventualmente, si estamos hablando de bienes comercializables -como un cuadro, o un disco- también el valor de cambio, el precio). $\mathrm{Si}$ el problema esta en el 'uso', o si se interpreta 'uso' como equivalente a 'consumo', entonces estamos simplificando el concepto de 'uso', que es algo muy distinto a 'consumo' (Lull 2007:195-197, refiriéndose a los objetos "arqueológicos"). Claro que hay muchas activaciones patrimoniales que presentan un sesgo comercial, pero, 1) no son todas, y 2) ¿toda mercantilización tiene los mismos efectos perversos? ¿Se dan los mismos procesos de socialización en cualquier tienda de 'El Corte Inglés' que en 'Novedades Carmiña'?

Ahora bien, este argumento puede servir para desenmascarar (o no) ciertas formas de crítica, aquellas que no son coherentes con una visión holística de la realidad social, porque aplican la crítica sólo a aquellos segmentos de la realidad que les interesa criticar. Pero no sirve para desentrañar los entresijos del valor patrimonial. ¿Qué quiere decir que la gente "use un sitio patrimonial”? ¿Hasta dónde la cultura es un ámbito en el que se pueden discernir con facilidad los valores que emergen en su seno?

Asumamos, con cautela, que el patrimonio entra, en la medida en que es una producción cultural actual, dentro de ese campo difuso y en crisis que se viene denominando, desde hace tiempo, "industrias culturales". La crítica de las industrias culturales es antigua (para una visión sintética de su evolución véase O'Connor 2011), pero sus argumentos mantienen su peso. Lo que aquí nos interesa es destacar, como afirma O'Connor (2011: 31), la dificultad de comprender las industrias culturales en los términos clásicos (valor de uso y valor de cambio), porque no se les puede aplicar el concepto de plusvalía igual que a una manufactura, porque no hay forma de anticipar el uso, y porque la gestión del capital humano que las genera es mucho más compleja que la de la mano de obra asalariada. En suma, ¿cómo se puede distinguir en la industria cultural el 'valor de uso' del 'valor de cambio'?

Según O’Connor (2011: 34), que sigue aquí a varios autores, el valor de uso "representa ese momento de autonomía en el núcleo mismo de la forma de producto cultural". Así:

"La autonomía del valor de uso cultural no se afirma contra el valor de cambio per se (los ingresos así como mucha estima profesional provienen del mercado) sino en diferentes puntos dentro del contexto específico ético, político y estético, dentro del cual se genera ese beneficio" (O’Connor 2011: 35).

De manera que, si esto parece razonable cuando estamos hablando de productos culturales directamente comercializables (libros, discos, representaciones teatrales...), más razonable parece en contextos patrimoniales, donde lo que se comercializa (y no siempre, ni necesariamente) son una serie de servicios a su alrededor (es interesante el trabajo de Vicente 2007, que distingue claramente entre estos dos aspectos). Es por esto que son factibles una buena película (por la que no obstante debes -o debías- pagar una entrada), o un buen libro (que puedes comprar); y es por esto que una puesta en valor de calidad depende de si se han invertido los recursos necesarios para ello, pero también de cómo se gestione en tanto servicio cultural (de si se siguen invirtiendo recursos en su mantenimiento y uso, independientemente de dónde provengan dichos recursos), y, sobre todo, de que permita un 'buen uso' del patrimonio. La buena calidad de un producto cultural no depende de si entra o no entra en una dinámica mercantil, lo que no significa que no haya productos (también en el campo patrimonial) cuya calidad es baja porque han primado los criterios comerciales sobre otros criterios; es decir, no sólo se ha entrado en una dinámica mercantil, sino que es su lógica la que orienta la producción y selección de unos determinados bienes para su puesta en valor (Bendix 2009: 266).

Como dice Huyssen (2002: 26) "la calidad sigue siendo un asunto a definir caso por caso":

"Aun cuando el Holocausto ha sido mercantilizado interminablemente, no significa que toda mercantilización lo trivialice indefectiblemente como hecho histórico. No existe un espacio puro, exterior a la cultura de la mercancía, por mucho que deseemos que exista. Por lo tanto, es mucho lo que depende de las estrategias específicas de representación y del contexto en que ambas son puestas en escena" (Huyssen 2002: 25) . 
Ha habido muchos intentos de clasificar y categorizar los valores que intervienen en las activaciones patrimoniales (William Lipe, Stanley Price, -citados en González 1999-, así como Ballart 1997 o Mason 2002, entre otros). Por lo general, todos inciden en señalar que hay valores asociativo-simbólicos, documentales, estéticos, económico-utilitarios... Estas dimensiones se mezclan en diferentes tipos según quién haya realizado la clasificación.

Tim Darvill (1994) habla de 'sistemas de valores' (de existencia, de opción y de uso, y en este último entran los valores científicos, artísticos, educativos, recreativos, simbólicos, asociativos y económicos). David Throsby (2002) habla directamente de 'capital cultural', que suena acertado pero no es fácil de definir (en un contexto económico, 'capital cultural' no se corresponde con el concepto sociológico definido por Bourdieu -competencia cultural del individuo como marca de estatus-, porque este último se correspondería, en términos económicos, con el 'capital humano', aunque más abajo matizaremos esto). Partiendo del hecho de que una entidad patrimonial se conforma a partir de un proceso sucesivo de agregación de valores (desde la creación de la entidad, en un momento pre-patrimonial, pasando por la inversión de trabajo en su estudio y conservación, así como en su adecuación, y la generación de valor más allá de la propia entidad), este autor distingue (aunque no son sistemas excluyentes), los valores de no-uso (existencia, opción y legado) y de uso (estético, espiritual, social, histórico, simbólico).

Nuestra propuesta parte de la distinción entre esferas vitales, de acción (lo que Habermas 1999 a y b denomina 'Mundo de la Vida') que son la cognitivo-instrumental, la práctico-moral y la prácticoestética, y 'medios del sistema' (económico -en su dimensión mercantil- y político -en su dimensión administrativa-). Nos hemos referido con detalle a este punto en otros lugares (Barreiro 2006a, 2006b), por lo que no abundaremos aquí en ello. En todas estas esferas y medios, cuando se produce una activación patrimonial, emergen valores. Se trataría, entonces, de intentar esbozar qué tipos de valores se generan ahí, y si es posible orientar nuestras acciones en función de qué valores queremos maximizar (los propios de un Mundo de la Vida des-cosificado) y cuáles queremos minimizar o erradicar (los que provienen de los medios tecnocrático y de mercado). Nuestra propuesta tampoco presupone que esta deconstrucción de los valores emergidos en una activación patrimonial pueda ser fácilmente (ni siquiera que pueda ser factible) conceptualizable, formalizable y, ni mucho menos, cuantificable (como señala Carman 2009: 200-202 respecto a los intentos de English Heritage y de Heritage Lottery Fund por cuantificar los valores del patrimonio), pero sí que puede contribuir a entender mejor qué dimensiones vitales entran en juego cuando tiene lugar una patrimonialización. También Mason señala la dificultad de modelizar algo tan complejo, al tiempo que reclama la necesidad de intentarlo:

\begin{abstract}
"While the subjectivity and contingency of heritage values make it difficult to establish a clear framework or even a nomenclature of values $(\ldots)$, this is precisely what is needed to facilitate the assessment and integration of different heritage values in conservation planning and management" (Mason 2002:9).
\end{abstract}

\section{Valores de no-uso}

Quizás lo más apropiado sea comenzar, precisamente, por estos posibles valores de no-uso, o valores de existencia, opción y legado (Throsby 2002: 103). Entidades (existencia) a cuya patrimonialización se renuncia (opción), precisamente, para permitir que las generaciones futuras puedan hacerlo conforme a sus propias necesidades y criterios (legado). Reservar un elemento para las generaciones futuras, sin embargo, y en nuestra opinión, no deja de ser un uso: motivado por una actitud que conscientemente reniega de patrimonializar dicho elemento hoy, pero es una utilización también. En cualquier caso, es un uso (o no-uso) legítimo, pero esta legitimidad exige un proceso de negociación que, en ocasiones, puede ser muy conflictivo, dado que depende en gran medida de qué agentes sociales estén involucrados en el proceso y con qué intereses.

\section{Valor instrumental}

A pesar de la complejidad de desgajar el concepto de valor de 'instrumentalidad' de otros valores de uso asociados (ya que todo uso es una forma de instrumentalización), es necesario tipificarlo para que el uso instrumental de determinados elementos patrimoniales (porque no todos lo poseen) no quede marginado. Puede ayudarnos a precisar esto el pensar en una instrumentalización primaria: esto es, un uso igual o muy aproximado al uso original para el que el elemento patrimonializado fue concebido (casi siempre, no como una entidad patrimonial, sino como una entidad para ser usada conforme a una función concreta). Dentro del patrimonio arquitectónico hay múltiples ejemplos de pervivencia de usos (habitabilidad) aunque varíen, en ocasiones ostensiblemente, las funciones originales.

\section{Valor documental}

El valor más evidente y, en muchos casos, el único valor que se le reconoce al patrimonio (sobre todo 
desde el ámbito experto), dándose incluso la contradicción de que es en su nombre (en nombre del conocimiento, histórico sobre todo) que se denuesta la patrimonialización de que una entidad puede ser objeto, es el valor documental. Para una visión crítica como la que hemos visto, este valor documental precede al patrimonio, es anterior al proceso de patrimonialización; y, precisamente, es este proceso el que hace que su valor documental (la información que puede suministrar) se pervierta al transformar el registro en otra cosa (el patrimonio).

Sin embargo, como decíamos al principio, aunque registro y patrimonio no sean lo mismo, sí se pueden producir al mismo tiempo. Y, sobre todo, la transformación del registro en patrimonio no tiene por qué conllevar una pérdida del valor documental: en primer lugar, porque ese valor se mantiene, transformado, en la entidad patrimonial; en segundo lugar, porque no toda la información extraída va a convertirse en conocimiento ni va a ser patrimonializada, sino que va a ser archivada (que podría ser una variante de patrimonialización, en la que no entraremos); es decir, no va a desaparecer.

El valor documental (que se produce en la esfera cognitiva) no emerge por sí solo: necesita una mediación, que es la extracción de información, la transformación en conocimiento y su transmisión. Aunque no se dé una patrimonialización dirigida jerárquicamente por una disciplina, y nos involucremos en un proceso participativo y horizontal, la disciplina sigue jugando un papel mediador clave. Porque el saber tradicional corporeizado en torno a una entidad patrimonial se convierte en un conocimiento susceptible de ser transmitido cuando hay una mediación antropológica (ésta es una de las paradojas a las que se refiere Ariño 2010: la mediación fosiliza, pero sin mediación no hay patrimonialización). Lo que el patrimonio puede evocar sin mediación son otros valores (que veremos), pero en poca medida valor documental; incluso el proceso de autoconciencia y reflexión inducido por la contemplación de restos arqueológicos (sin mediación o con ella) puede generar algo semejante a un sentido de la historia, pero no en clave cognitiva, sino estética.

\section{Valor estético}

"En la contemplación de las ruinas, el argumento se reduce al mínimo y deja visible en toda su amplitud el horizonte, el tránsito de las cosas de la vida; es el raro privilegio de que gozan y que es causa de su fascinación. También las cosas gastadas muestran el paso del tiempo y en el caso de un objeto usado por el hombre algo más: la huella, siempre misteriosa, de una vida humana grabada en su materia. Un cepi- llo usado, un zapato viejo, un traje raído, casi llegan a alcanzar la categoría de ruina. Porque ruina es solamente la traza de algo humano vencido y luego vencedor del paso del tiempo (Zambrano 1973: 238-9).

Este valor estético, sin embargo, no sólo concierne a la generación de una emoción existencial en el sentido referido por María Zambrano, a quien, en consonancia con su racionalismo poético, le bastaba la contemplación de las ruinas, sin mediación científica, para alcanzar cierto tipo de conocimiento (algo que también sostiene, por ejemplo, Prats 1997: 64).

Una entidad patrimonial (sobre todo si su función es estética en origen, como sucede con las obras de arte) también puede motivar la recreación, el mero goce estético, como el que produce, por ejemplo, la contemplación de las ruinas en el parque de San Domingo de Bonaval, en Santiago, cohabitando por las obras de Chillida.

Y también produce una inspiración creativa, la reinversión de esa emoción estética en actos creativos ex novo (inspiración que es, por otro lado, uno de los criterios extra-científicos de las activaciones, Prats 1997: 24-5). Esta dimensión inspiradora es, de todos modos, difícilmente conceptualizable, ya que concierne tanto al poder evocador de determinadas entidades, como al escurridizo vínculo entre ellas y sus "representaciones". Por otro lado, los procesos de patrimonialización terminan realimentándose con parte de estas representaciones: en realidad, eso es la conversión de una obra humana en "clásico".

\section{Valor político}

En la esfera práctico-moral emerge el valor político, que es el que propicia que una comunidad se identifique (como tal) y que un individuo se reconozca (como miembro de dicha comunidad) a través del patrimonio. Esta definición es bastante simple, ya que, en realidad, habría que hacer referencia a cómo en torno al patrimonio se generan identidades colectivas (su dimensión simbólica lo propicia). El tema de la identidad en relación con el patrimonio ha sido abordado desde muy diversos puntos de vista (Ballart 1997, García Canclini 1999, Criado 2001, Santamarina 2005, Herrero 2011; sólo por citar algunos ejemplos) y es recurrente en cualquier tratamiento teórico del patrimonio, además de un concepto doblemente escurridizo.

Primero, porque en la dimensión identitaria reside el deslizamiento de la forma político-comunitaria del sentimiento de pertenencia (lo que incluye, por ejemplo, el sentimiento de pertenencia a una comunidad religiosa concreta - una parroquia, materializada en una iglesia-, que debe ser distinguido 
del valor instrumental que tiene una iglesia por el mero hecho de servir de lugar de reunión a los feligreses) a la forma político-administrada (que incluiría también el sentimiento de pertenencia a una institución -por seguir con el ejemplo, la Iglesia católica-). Esto es: la transformación de un sentimiento identitario ligado a un sentido concreto de lugar, en un sentimiento ligado a la identificación con una comunidad política institucionalizada. Lo segundo no implica la desaparición de lo primero, por supuesto, pero sí introduce una mediación que proviene del mundo del poder político, de la administración, en términos habermasianos, con todo lo que ello implica.

Segundo, porque en nuestro mundo globalizado, los procesos de identidad han dejado de estar exclusivamente ligados a la pertenencia; o, al menos, a una pertenencia basada en la proximidad. Esto es lo que ha posibilitado, por ejemplo, el nacimiento y consolidación de conceptos como Patrimonio Mundial o de la Humanidad: elementos patrimoniales a los que se ha querido dotar de un sentido de pertenencia global, lo que connota aspiraciones universalistas que pueden ser controvertidas. También es lo que posibilita que los procesos de identificación se manifiesten en un nivel distinto al de la pertenencia a una comunidad en términos geográficos, como puede ser una comunidad ideológica (por ejemplo: los represaliados, españoles o extranjeros, del franquismo), o étnica (por ejemplo: los judíos o gitanos reprimidos por el fascismo), religiosa, etc.

\section{Patrimonio como recurso}

Para que emerjan estos valores tiene que darse una acción social, sea de forma directa (como ocurre con los valores estético y político-comunitario, y, en menor medida, con el documental), mediada (con la participación de saberes expertos que, por sí solos, o mediante la metabolización de saberes tradicionales, hacen emerger nuevos valores -documental- o que refuerzan valores ya existentes -estético, político-comunitario-) o sistémica (con lo que nos desplazamos de las esferas del Mundo de la Vida a los Medios del Sistema, con la transformación del valor político en valor político-administrado).

En este sentido, hay que considerar el concepto de patrimonio como recurso, es decir, como medio para generar valores añadidos; propiamente, para activar la circulación de capital económico (más que para producirlo, aunque siempre hay procesos productivos implicados en el patrimonio), y para generar $c a$ pital humano (y aquí sí es pertinente la relación con el concepto de 'capital cultural' de Bourdieu, como señala Carman 2009: 195-6: a través del patrimonio los individuos pueden incrementar su capital cultural, es decir, se genera capital humano).

\section{Valor económico}

El valor económico del patrimonio es ya de por sí un concepto suficientemente problemático como para intentar aquí deconstruirlo, aunque intentaremos aportar algunos elementos para el debate.

Suele hablarse del valor económico del patrimonio en términos de recurso para la generación de riqueza y crecimiento (Vicente 2007, por ejemplo). Pero esto sólo es factible para ciertos elementos patrimoniales, relacionados con activaciones más macro que micro (por usar los términos de Prats 1997). Aunque, como hemos dicho antes, el patrimonio es más un medio para activar la circulación de riqueza que un generador de la misma, negar que ciertas activaciones, más simples o más complejas, generan un efecto de incremento en la actividad económica es simplemente ignorar la realidad (no hay más que darse un paseo por cualquiera de los cascos históricos de nuestras ciudades para verlo: incluso en el caso de Gasteiz, por ejemplo, es evidente que la actividad que giró y gira en torno a la Catedral Vieja ha funcionado como motor de la regeneración urbana del mismo; Azkarate 2009). Otra cosa es que muchas activaciones antepongan criterios de rentabilidad económica a otros criterios, o que los procesos de regeneración sigan criterios estandarizados que implican una homogeneización en los usos sociales del espacio; pero tanto en un caso como en otro, eso no significa que siempre tenga que ser así.

No obstante, la relación entre turismo y patrimonio debe ser analizada, sin duda, no solo desde un punto de vista instrumental (Pérez-Juez 2006), sino desde un punto de vista crítico (Pereiro 2009). Porque el turismo (conviene detenerse en este punto), igual que el patrimonio, es un fenómeno típicamente moderno (más reciente y más impactante; un buen análisis de la relación entre ambos puede verse en Hernández 2005: 159-192), por lo que está igualmente atravesado por contradicciones. Pero, antes de hacer una enmienda a la totalidad y renegar de la posibilidad de que exista algo llamado "turismo patrimonial", convendría tener en cuenta dos cosas:

-No todo acto turístico es un momento de reificación y alienación: el patrimonio es un medio privilegiado para posibilitar un acceso diferente a la realidad y para enriquecer la experiencia vital del visitante (Herrero 2011: 303).

-No son lo mismo las activaciones patrimoniales de pequeña escala, que las grandes activaciones patrimoniales, promovidas y apoyadas por corporaciones y grandes empresas que utilizan el patrimonio para generar cuantiosos beneficios.

A través del patrimonio, por lo tanto, podemos aspirar a que el turismo sea una actividad más integrada y sostenible. 
Pero la dimensión económica del patrimonio va más allá de los ingresos generados de forma directa por el turismo (Rypkema 2009, Greffe 2009). En la medida en que el patrimonio es un medio de primera importancia para implementar políticas alternativas de participación y democratización, de generación de un sentido del lugar, de reapropiación del Mundo de la Vida, también puede serlo para promover iniciativas económicas a escala local, cimentadas en los principios de la sostenibilidad y la autogestión.

Por lo tanto, actuar sobre el patrimonio también puede contribuir a desligar una esfera consustancial de la actividad humana (la económica) de su forma específica bajo el capitalismo (el mercado) y por lo tanto, al igual que ocurre con su valor político (desligando la forma comunitaria de la forma administrada), a reintegrarla en el Mundo de la Vida.

\section{Valor educativo}

Esto último nos conduce, además, al valor educativo o formativo del patrimonio. En cierto modo, $\mathrm{y}$ desde una perspectiva amplia, es lo que justifica todo lo que podamos hacer con el patrimonio y en torno a él (desarrollo de conocimientos, habilidades, emociones y actitudes a través de la experiencia para la transformación de un contexto, Fontal 2003). Es por esto que consideramos el valor educativo o formativo como un valor añadido: porque el patrimonio contribuye a (es un medio para) la formación integral de la persona y, por lo tanto, para el desarrollo humano.

En cualquiera de los tres ámbitos educativos, formal (dentro del sistema de formación reglado), no formal (con comunidades escolares pero al margen del sistema reglado) e informal, es factible diseñar estrategias de enseñanza-aprendizaje. Esto incluye, por supuesto, la formación especializada: es decir, la formación de futuros expertos en patrimonio, en cualquiera de sus variantes. En cualquier caso, la pedagogía no emerge de la linealidad o unidireccionalidad, sino también de la horizontalidad: del hacer cosas juntos, aprender con, co-construir el patrimonio entre los distintos agentes sociales: educadores, alumnos, visitantes, vecinos y expertos.

Para nuestra propuesta, por lo tanto, es vital una ampliación del mismo concepto de educación patrimonial (en línea con la propuesta de Fontal 2003 y Cuesta et al. 2009), entroncando con la tendencia a la generación de comunidades de patrimonio, su construcción participativa como medio y modo de desarrollo y la aproximación epistemológica y práctica al contexto educativo (desde las disciplinas especializadas -pedagogía, psicología social, didáctica-), aunque esto nos conduce ya a un segundo apartado, relacionado con la interacción de múltiples disciplinas en esta estrategia de socialización.

\subsection{Multidisciplinariedad y apertura}

Abordar el patrimonio como problema científico requiere una estrategia multidisciplinar que vaya más allá de la interdisciplinariedad que tiene lugar en el plano de aplicación. Requiere saberes expertos en el plano de la mediación: en un primer nivel, más concreto, las disciplinas tradicionales complementarias (la museología, la conservación, y sus actualizaciones teóricas). En un nivel más genérico, la antropología (desde su vertiente más relacionada con los propios procesos de patrimonialización, como señala Mason 2002:20), por conferirle a nuestras acciones en torno al patrimonio una perspectiva holística, centrada en la vivencia patrimonial; pero también las ciencias de la educación, tanto a nivel teórico (imbricando la educación patrimonial como uno de los ejes de la estrategia) como práctico (con diseños y programas aplicables), o las ciencias de la información (orientadas a una difusión, en su sentido más amplio, de la conciencia, la reflexión y la participación en las activaciones patrimoniales).

La apelación a la colaboración disciplinar no se puede limitar al ámbito de lo técnico o práctico; es un imperativo ante las estrategias de fragmentación e individuación del discurso hegemónico, que se han agudizado al mismo tiempo que se ha expandido la globalización.

Una ciencia como la que se propone, abierta, cooperativa e intersubjetiva, es necesaria para mitigar esta estrategia hegemónica. Pero, en todos estos sucesivos momentos de ampliación disciplinar, los saberes expertos implicados no pueden contribuir a la misma sin considerar que su participación en la socialización del patrimonio es sólo una parte de ella. Una ciencia (en este caso, la arqueología) que no se produzca en estrecha relación con la sociedad, que no se dé como una práctica socializada, sigue siendo una ciencia insuficiente, y el patrimonio es el medio idóneo para que esta socialización de la arqueología (y, en consecuencia, del patrimonio) se produzca de forma plena.

Con la arqueología, esto es especialmente delicado por dos razones. En primer lugar, porque, para otras disciplinas relacionadas con el patrimonio (como la antropología o incluso la historia), el contexto habitual de trabajo implica ya una interacción con el medio social, mientras que, en el caso de la arqueología, éste casi siempre ha desaparecido. En segundo lugar, es más delicado porque la necesaria apertura disciplinar conlleva ciertos riesgos de desesencialización, lo cual, cuando afecta a todo un sector social (el de los arqueólogos profesionales que trabajan fuera de las instituciones), ya de por sí desestructurado, produce un efecto sinérgico perverso. 
La necesaria reubicación de la arqueología en un posicionamiento posnormal (en el sentido proporcionado por Funtowicz y Ravetz 2000), en el que la generación de conocimiento y la propia práctica científica deben tener lugar en el seno de las comunidades de patrimonio (arqueología con la gente, en comunidad: Rolland 2006), no puede ser un salto en el vacío, ni puede producirse sin integrar a aquellos sectores de la disciplina que, habiendo emergido en otros contextos ahora en crisis, se ven, precisamente, desubicados.

Por un lado, cualquier propuesta de arqueología pública, incluso cualquier propuesta que pretenda ir más allá de la arqueología pública (Ayán et al. 2011), como la community archaology, no puede dejar de lado lo que la arqueología ha sido hasta el momento: al menos, no puede dejar de lado unas cualidades, las propias de una disciplina científica, el rigor técnico y la aplicación de un saber experto a la generación de conocimiento específico. En todo caso, debe formar parte de la estrategia integral de investigación que hemos venido proponiendo el diseñar e implementar los conceptos y procedimientos necesarios para que la socialización de la arqueología no merme la especificidad del saber arqueológico, ni de ninguno de los saberes específicos vinculados al patrimonio. Una estrategia como la que se propone desde la arqueología pública (y, sobre todo, desde la community archaeology) busca deconstruir los principios legitimadores en los que se basa el DPA, pero corre el riesgo de arrastrar en el mismo movimiento a los discursos que la fundamentan, basados en el ejercicio crítico de la disciplina (según lo perfilan Fernández 2006a, 2006b y González-Ruibal 2012, González Ruibal en este volumen). La community archaeology no debería propiciar el intrusismo, sino un enriquecimiento de dicho territorio profesional, y su plena socialización ${ }^{5}$. La investigación en arqueología también tiene que atender a estos posibles dilemas, propiciados por el contexto político y económico en que tienen lugar estas interacciones, y anticiparse a ellos.

Por otro lado, cualquier propuesta integradora, y es lo que hemos intentado plantear en este texto, no sólo debe orientarse hacia una integración externa: esto es, de la arqueología en las activaciones patrimoniales socializadas, sino interna. No podemos permitirnos (ni ética ni epistemológicamente) el lujo de renunciar al potencial y al capital humano acumulado a lo largo de las últimas décadas al margen de las instituciones, que ahora se encuentra en el atolladero de buscar nuevas fórmulas para su propia viabilidad y supervivencia. Una estrategia de socialización del patrimonio como la que estamos proponiendo requiere también la bús- queda, integrada, de nuevos nichos sociales para la arqueología.

Estos nichos, a la vista de la situación global de crisis del modelo capitalista (al menos en nuestro contexto político), deberían ir no sólo más allá de los contextos hasta ahora frecuentados por la arqueología comercial (las obras públicas, la gestión territorial y ambiental), sino más allá de los nichos que, a primera vista, aparecen como alternativos: el turismo y las industrias culturales, las Tecnologías para la Información y la Comunicación...

\section{Arqueología, patrimonio, utopía}

No es fácil ser optimista respecto al futuro, pero no sólo respecto al futuro de la arqueología. Creemos que el modelo económico en el que vivimos, y en el que la arqueología, como cualquier otra disciplina científica, y como cualquier otra profesión, ha jugado y juega un papel, está abocado a su transformación, más tarde o más temprano, en otra cosa bien distinta. Y esta transformación no va a ser necesariamente para mejor: cualquier pronóstico medianamente realista sobre la evolución futura de la humanidad no puede ser, hoy por hoy, tan ingenuo.

Pero nuestra idea, profundamente dialéctica, es que toda realidad engendra en sí misma el germen de sus propias transformaciones. En las contradicciones y resquicios del sistema, que siempre existen aunque la propia discursividad hegemónica lo oculte (y los movimientos sociales indignados son una prueba evidente de este potencial de transformación oculto), es donde la arqueología y las restantes ciencias sociales deben trabajar. Renunciar a hacerlo en el campo específico del patrimonio es un lujo que no nos podemos permitir.

\begin{abstract}
"Por mucho que el museo, consciente o inconscientemente, produzca y afirme el orden simbólico, hay siempre un excedente de significado que sobrepasa las fronteras ideológicas establecidas, abriendo espacios a la reflexión y la memoria antihegemónica" (Huyssen 2002: 45).
\end{abstract}

Hoy por hoy, un horizonte para orientar nuestra acción sigue siendo, por lo tanto, imprescindible. Si el patrimonio es memoria, y debe ser registrado y estudiado, también debe ser utilizado para algo más. Es conocimiento y es valor, sí, y también es acción y proyección.

"Heritage is a cultural and social process; it is the experiences that may happen at sites or during the acting out of certain events; it is a process of remembering and memory making -of mediating cultural and social change, of 
negotiating and creating and recreating values, meanings, understandings and identity. Above all, heritage is an active, vibrant cultural process of creating bonds through shared experiences and acts of creation" (Smith 2006: 307-8).

Pero sin una crítica constante y reflexiva, consciente de las coordenadas culturales en que nos movemos, será difícil articular una estrategia que mantenga ese margen de autonomía frente a la práctica discursiva globalizadora y hegemónica.

Las utopías que han caído son aquellas que se apoyaban en el potencial liberador del trabajo y la producción (el reino de la abundancia). Esa capacidad, en realidad, ya ha sido posible bajo el capitalismo y la revolución científico-tecnológica, sólo que con una desigualdad superlativa y creciente, $\mathrm{y}$ a un precio humano (por destrucción de vidas y modos de vida) y ecológico (por calidad y cantidad) inasumible. Por lo tanto, la nueva utopía (o, mejor dicho, una utopía renovada, ya que no anula la esencia emancipadora de las anteriores; no es una alternativa radical, sino evolucionada de aqué- llas) debería mirar hacia el futuro, sí, pero no con las gafas del Progreso (salvo que entendamos por 'Progreso' un camino que nos lleve hacia otro sitio que el del crecimiento económico perpetuo), sino de la Sostenibilidad.

"Reducir la velocidad en lugar de acelerar, expandir la naturaleza del debate público, tratar de curar las heridas infligidas por el pasado, nutrir y expandir el espacio habitable en lugar de destruirlo en aras de alguna promesa futura, asegurar el 'tiempo de calidad' - ésas parecen ser las necesidades culturales no satisfechas en un mundo globalizado y son las memorias locales las que están íntimamente ligadas con su articulación" (Huyssen 2002: 38).

Si la esperanza es un deseo, la utopía es un proyecto de futuro; quizás impreciso y errático, pero de futuro. Y el patrimonio es parte de ese futuro:

"The past was different, the relics of the past tell us; they also tell us the future will be different" (Fairclough 2009: 127).

\section{Notas}

1. Para una idea general véase, por ejemplo, la sección monográfica que le dedicó recientemente a la carrera investigadora en arqueología la Revista d'Arqueologia de Ponent (Armada 2010: 229-70) o Ruiz 2009.

2. Es muy ilustrativa de esto la película Los Narradores del Caraguatá, accesible en el siguiente sitio web: http:// hdl.handle.net/10261/25625.

3. Incluso no deberíamos descartar, aunque aquí no propongamos nada en concreto, que esta transformación de la realidad patrimonio implique su reconceptualización hasta el punto de redenominarla, con un término diferente a este, para referirnos a una parte esencial de ella (su potencial transformador, por decirlo en dos palabras), en la medida en que ya se halla fuertemente connotado por la otra parte (su potencial cosificador), de la que queremos prescindir.

4. La afirmación de Huyssen no significa que haya que renunciar a la existencia de un espacio "exterior a la cultura de la mercancía", sino que la lucha por el mismo tiene que tener lugar, forzosamente, dentro de ella.

5. "On the stage of the theatre of memory, archaeology and its activities are the bringers of materiality. It is possible to transfer the actions that constitute archaeology from the conceptual space that is a professional territory onto the stage. Whilst acting on the stage, everyone is participating in the social construction of archaeology within the academic and professional territory. On the bigger stage of the theatre of memory, there are many more actors than we find in the safe confines of the professional territory. Here, we find the public in all its forms, helping to construct an archaeology that may or may not be appreciated by the professional archaeologists" (Kenny 2009: 223-224).

\section{REFERENCIAS Bibliográficas}

ArIÑO, A. (2010): La patrimonialización de la cultura y sus paradojas postmodernas. Nouve pratiche di comunità. I patrimoni culturali etnantropologici fra tradizione e complesità sociale (D. Porporato, ed.), Omega Edizioni, Torino: $15-32$.

ArÉVAlo, J.; DíAz, I. (1997): Consideraciones sobre la relación coste/calidad en los Estudios de Impacto Ambiental. Avances en evaluación de impacto ambiental y ecoauditoría (M. Peinado; I. Sobrini, ed.), Trotta, Madrid: 69-83. 
ArmadA, X.L. (Ed) (2010): Claves y problemas de la carrera investigadora en arqueología. Introduciendo al debate. Revista d'Arqueologia de Ponent, 20: 229-235.

AyÁn, X.; GonzÁlez, M.; Rodríguez, R. (2011): Más allá de la Arqueología Pública: arqueología, democracia y comunidad en el yacimiento multivocal de A Lanzada (Sanxenxo, Pontevedra). VIII Seminari d'arqueologia y ensenyament - Barcelona, 31 de març - 2 d'abril, 2011. Actes preliminars.

AzKarate, A. (2009): Reflexiones desde una universidad que aún no existe, sobre patrimonio y socialización. (Un estudio de caso: Vitoria-Gasteiz, la ciudad de las tres catedrales). XXXV Semana de Estudios Medievales de Estella. La Historia Medieval. Percepción académica y percepción social (21-25 de julio de 2008), Pamplona, Gobierno de Navarra: 285-304.

BALlaRt, J. (1997): El patrimonio histórico y arqueológico: valor y uso. Ariel, Barcelona.

Barreiro, D. (2006a). Conocimiento y acción en la Arqueología Aplicada. Complutum, Vol. 17: 205-219.

BArreiro, D. (2006b). La aureola perdida. Propuesta para una arqueología aplicada. Arqueoweb 8 (1). [URL: http://www.ucm.es/info/arqueoweb/pdf/8-1/barreiro.pdf]. Acceso el 31/05/2012.

Barreiro, D. (2009): La Evaluación de Impacto Ambiental y el Patrimonio Cultural. Evaluación de impacto ambiental. Evolución normativo-jurisprudencial, cuestiones procedimentales y aplicación sectorial (A. Nogueira, dir.), Atelier, Barcelona: 281-94.

Barreiro, D. (En prensa). Arqueológicas 2: Hacia una Arqueología Aplicada. Bellaterra Arqueología, Barcelona.

Bendix, R. (2009): Heritage between economy and politics. An assessment from the perspective of cultural anthropology. Intangible Heritage, (L. Smith; Akagawa, N, eds.), Routledge, Londres: 253-269

Berman, M. (1988). Todo lo sólido se desvanece en el aire. Siglo XXI, Madrid.

Bermejo, J. C. (2007): Flatus Vocis. Genealogía de una palabra sin sentido: patrimonio. Habis, 38: 305-328.

Carman, J. (2009). Where the Value Lies: The Importance of Materiality to the Inmaterial Aspects of Heritage. En Waterton y Smith 2009: 192-208.

Castilla, C. (1995): La memoria y la piedra. Memòria 1990-1992. Patrimoni: memòria o malson? (A. González Moreno-Navarro, coord.), Servei de Patrimoni Arquitectónic Local, Barcelona: 9-14.

Castillo, A. (2006): Reflexiones sobre la enseñanza e investigación de la gestión del patrimonio arqueológico en la universidad española. Arqueoweb 8 (1). [URL: http://www.ucm.es/info/arqueoweb/pdf/8-1/castillo.pdf]. Acceso el 31/05/2012.

Cerdeño, L.; Castillo, A. Sagardoy, T. (2005): La evaluación de impacto ambiental y su repercusión sobre el patrimonio arqueológico en España. Trabajos de Prehistoria, 62 (2): 25-40.

CONVEnio de FARo (2005): Convention on the Value of Cultural Heritage for Society. [URL: http://www.coe.int/t/ dg4/cultureheritage/heritage/identities/default_en.asp]. Acceso el 31/05/2012.

Criado, F. (1996) Hacia un modelo integrado de investigación y gestión del Patrimonio Histórico: La cadena interpretativa como propuesta. Boletín del Instituto Andaluz del Patrimonio Histórico, 16: 73-8.

CRIADO, F. (2001): La memoria y su huella. Claves de razón práctica, 115: 36-43

Criado, F. (2012): Arqueológicas. La razón perdida. Bellaterra arqueología, Barcelona.

Cuesta A. V.; Dimuro J.; Gianotti C.; Muttoni M. (2009): De la investigación a la construcción participativa del patrimonio. Un programa de educación patrimonial y divulgación de la cultura científica en Uruguay. Arkeos, 4 (11). [URL: http://mileto.pucp.edu.pe/arkeos/content/view/225/26/]. Acceso el 31/05/2012.

Darvill, T. (1994): Monuments Protection Programme. Monuments Evaluation Manual. Parts I \& II. English Heritage, London.

Debord, G. (1999). La sociedad del espectáculo. Pre-Textos, Valencia.

Eco, U. (1968): Apocalípticos e integrados. Lumen, Barcelona.

FAirclough, G. (2009): New heritage frontiers. En VV. AA. 2009: 29-42.

Fernández Martínez, V.M. (2006a): Arqueologías críticas: el conflicto entre verdad y valor. Complutum, 17: 191-203.

Fernández Martínez, V.M. (2006b): Una arqueología crítica. Ciencia, ética y política en la construcción del pasado. Crítica Arqueología, Barcelona.

Fontal, O. (2003): La educación patrimonial. Teoría y práctica para el aula, el museo e Internet. Trea, Gijón.

Funtowicz, S.; Ravetz, J. (2000): La ciencia posnormal. Ciencia con la gente. Icaria, Barcelona. 
García Canclini, N. (1999): Los usos sociales del patrimonio cultural. Patrimonio etnológico. Nuevas perspectivas de estudio (E. Aguilar, ed.), Consejería de Cultura, Junta de Andalucía, Sevilla: 16-33.

González Méndez, M. (1999): Investigación y puesta en valor del Patrimonio Histórico. Planteamientos y Propuestas desde la Arqueología del Paisaje. Humanidades y Ciencias Sociales 1999. Tesis doctorales en CDRom. Universidade de Santiago de Compostela, Santiago de Compostela.

González-Pérez, C; Parcero-Oubiña, C. (2011). A Conceptual Model for Cultural Heritage. Definition and Motivation. Revive the Past: Proceedings of the $39^{\text {th }}$ Conference in Computer Applications and Quantitative Methods in Archaeology, Beijing, China, 12-16 April 2011.

GonZÁlez-RuiBAL, A. (2012): Against post-politics: a critical archaeology for the 21st century. Forum Kritische Archäologie 1: 156-166 [URL: http://www.kritischearchaeologie.de/fka/article/view/21/21]. Acceso el $31 / 95 / 2012$

GrefFe, X. (2009): Heritage conservation as a driving force for development. En VV. AA. 2009: 101-12.

Habermas, J. (1999a): Teoría de la Acción Comunicativa, I. Racionalidad de la acción y racionalización social. Taurus, Madrid.

Habermas, J. (1999b): Teoría de la Acción Comunicativa, II. Crítica de la razón funcionalista. Taurus, Madrid.

Harvey, D. (2001): Heritage pasts and heritage presents: Temporality, meaning and the scope of heritage studies. International Journal of Heritage Studies, Volume 7, 4: 319-338.

HeRnándeZ, G. M. (ed.) (2005): La memoria construida: patrimonio cultural y modernidad. Tirant lo Blanch, Valencia.

Hernández, G. M. (2005): La difusión del patrimonio cultural y el turismo. En Hernández 2005: 159-192.

HERNÁNDEZ, G. M. (2008): Un zombi de la modernidad: el patrimonio cultural y sus límites. La Torre del Virrey, 5: 27-38.

HerRero, N. (2011): La posmodernización de la tradición. Nuevos retos para la gestión del patrimonio. Revista de antropología social, 20: 293-307. [URL: http://revistas.ucm.es/index.php/RASO/article/view/36270/35119]. Acceso el 31/05/2012.

Huyssen, A. (2002): En busca del futuro perdido. Cultura y memoria en tiempos de globalización. Instituto Goethe, Fondo de Cultura Económica, México.

Kenny, J. (2009): Unpicking Archaology and Heritage: Can Understanding Territories and Community Help? En Waterton y Smith 2009: 209-229.

LulL, V. (2007): Los objetos distinguidos. La arqueología como excusa. Bellatera, Barcelona.

Mason, R. (2002): Assessing Values in Conservation Planning: Methodological Issues and Choice. Assessing the Values of Cultural Heritage. Research Report (M. De la Torre, ed.), The Getty Conservation Institute, Los Angeles: 5-30.

Moncusí, A. (2005): La activación patrimonial y la identidad. En Hernández 2005: 91-121.

O’Connor, J. (2011): Las industrias creativas y culturales: una historia crítica. Ekonomiaz, 78, 3: 24-47.

Parga-Dans, E.; Varela-Pousa, R. (2012). Caracterización socioeconómica de la Arqueología Comercial española. Resultados de la primera encuesta dirigida a empresas del sector. Complutum 22, 1, 2011: 9-25

Pereiro, X. (2006): Património Cultural: o casamento entre património e cultura. ADRA, 2: 23-41 Museo do Povo Galego, Santiago de Compostela.

Pereiro, X. (2009): Turismo Cultural. Uma visão antropológica. Colección PASOS Edita no 2, Asociación Canaria de Antropología, Tenerife. [URL: http://www.pasosonline.org/Publicados/pasosoedita/PSEdita2.pdf]

Pérez-Juez, A. (2006): Gestión del Patrimonio Arqueológico. El yacimiento como recurso turístico. Ariel, Barcelona.

Prats, Ll. (1997): Antropología y patrimonio. Ariel, Barcelona.

Querol, M. Á. (2011): El patrimonio cultural en las universidades españolas: no sólo una cuestión de tiempo. Patrimonio Cultural de España, 5: 75-89.

Rodríguez Temiño, I. (1998): Nuevas perspectivas en la protección del patrimonio arqueológico en el medio rural. Complutum, 9: 298-310.

Rolland, J. (2006): Práctica arqueológica y política. Complutum, 17: 185-190.

Ruiz Zapatero, G. (2009): ¿Qué arqueología enseñar en la universidad del siglo XXI? Complutum, 20: 225-238.

Renfrew, C; Bahn, P. (1993): Arqueología. Teorías, métodos y práctica. Akal, Madrid. 
RYPKEMA, D. (2009): Economics and the built cultural heritage. En VV. AA. 2009: 113-24

Santamarina, B. (2005): Una aproximación al patrimonio cultural. En Hernández 2005: 21-51.

Schlanger, N; Aitchison, K. (Eds.) (2010): Archaeology and the Global Economic Crisis. Multiple Impacts, Possible Solutions. Culture Lab Editions, Tervuren. [URL: http://www.ace-archaeology.eu/fichiers/25Archaeologyand-the-crisis.pdf]. Acceso el 31/05/2012.

Sмітн, L. (2006): Uses of Heritage. Routledge, Londres.

Sмiтн, L. (2011): El “espejo patrimonial”. ¿Ilusión narcisista o reflexiones múltiples? Antípoda. Revista de Antropología y Arqueología, 12: 39-63.

Throsby, D. (2002): Cultural Capital and Sustainability Concepts in the Economics of Cultural Heritage. Assessing the Values of Cultural Heritage. Research Report (M. De la Torre, ed.), The Getty Conservation Institute, Los Angeles: 101-117.

VICENTE, E. (2007): Economía del patrimonio y políticas patrimoniales: un estudio de la política del patrimonio histórico en Castilla y León. Instituto de Estudios Fiscales, Madrid.

VILLASEÑoR, I. (2011): El valor intrínseco del patrimonio cultural: ¿una noción aún vigente? Intervención, 3: 6-13.

VV. AA. (2009): Heritage and Beyond. Council of Europe, Estrasburgo.

Waterton, E.; Smith, L. (eds.) (2009): Taking Archaeology out of Heritage. Cambridge Scholars Publishing, Newcastle upon Tyne.

Waterton, E.; Smith, L. (2009): There is No Such Thing as Heritage. En Waterton y Smith 2009: 10-27

Watson, S. (2009): Archaeology, Visuality and the Negociation of Heritage. En Waterton y Smith (2009): 28-47.

Zambrano, M. (1973): El hombre y lo divino. Fondo de Cultura Económica, México. 